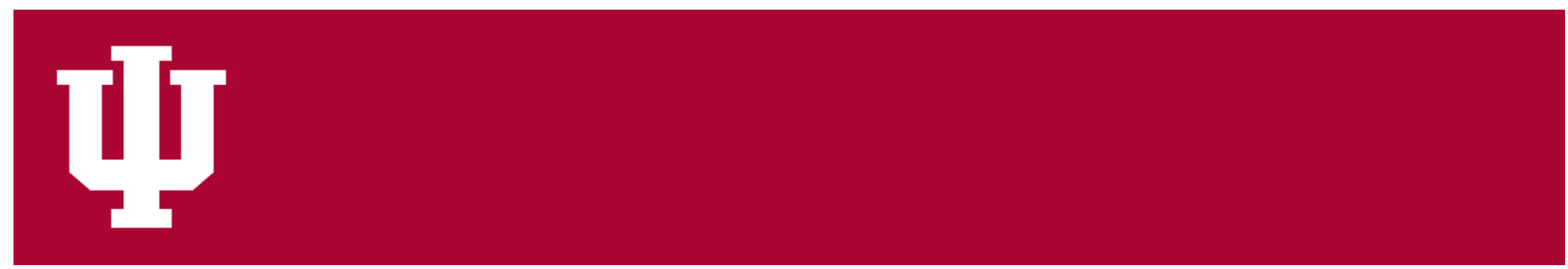

IUScholarWorks at Indiana University South Bend

\title{
Technological and Social Drivers of Change in the Online Music Industry
}

Fox, Mark A.

To cite this article: Fox, Mark. "Technological and Social Drivers of Change in the Online Music Industry." First Monday, vol. 7, no. 2, Apr. 2002, doi:10.5210/fm.v7i2.931

This document has been made available through IUScholarWorks repository, a service of the Indiana University Libraries. Copyrights on documents in IUScholarWorks are held by their respective rights holder(s). Contact iusw@indiana.edu for more information. 


\section{f $\mathrm{i}$ (i) $s+$ \\ $\mathbf{m} \not \tilde{n} \mathbf{d} @ \mathbf{q}$}

PEER-REVIEWED JOURNAL ON THE INTERNET

$\begin{array}{lllll}\text { HOME ABOUT } & \text { LOGIN REGISTER } & \text { SEARCH } & \text { CURRENT ARCHIVES } \\ \text { ANNOUNCEMENTS } & \text { SUBMISSIONS } & & \end{array}$

Home > Volume 7 Number 2 - 4 February 2002 >Fox

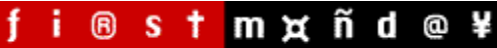

PEER-REVIEWED JOURNAL ON THE INTERNET

\section{Technological and Social Drivers of Change in the Online Music Industry \\ by Mark Fox}

\section{Special Issue Update}

This paper is included in the First Monday Special Issue: Music and the Internet, published in July 2005. Special Issue editor David Beer asked authors to submit additional comments regarding their articles.

This article complements two works that I wrote around the same time-in Popular Music \& Society ("E-commerce Business Models for the Music Industry", volume 27, number 2), and - along with Bruce Wrenn-in the International Journal on Media Management ("A Broadcasting Model for the Music Industry", volume 3, number 2).

Technological, social and legal changes have continued to shape the development of business models in the music industry. Notably, Apple Computer's iTunes service has been extremely successful with over 250 millions songs being downloaded and paid for. Today, some iPOD players are capable of storing 75,000 songs. Other major developments include the development of a download service (at 88 cents per song) by Wal-Mart, the world's largest company. And, Napster has been re-invented as a subscription site. Alternative approaches to copyright have been developed, most notably by the Creative Commons project.

I believe that the most interesting technological challenges today revolve around how technology can be used to help us decide-or decide for us)-what to listen to. Research on music information retrieval systems will no doubt lead to developments that make the way we access music today seem cumbersome.

\section{Abstract}

Considerable attention has been given to the legal implications arising from the distribution of music in a digital format via the Internet. However, less attention has been paid to the technological and social drivers of change in the music industry. This paper attempts to demonstrate the significant impact that social and technological forces have on the music industry, especially regarding lowering barriers to entry.

Contents

Introduction

Technological Drivers of Change

Social Drivers of Change

Discussion and Conclusions

\section{Journal Help}

U S E R

Username

Password

$\square$ Remember me

Login

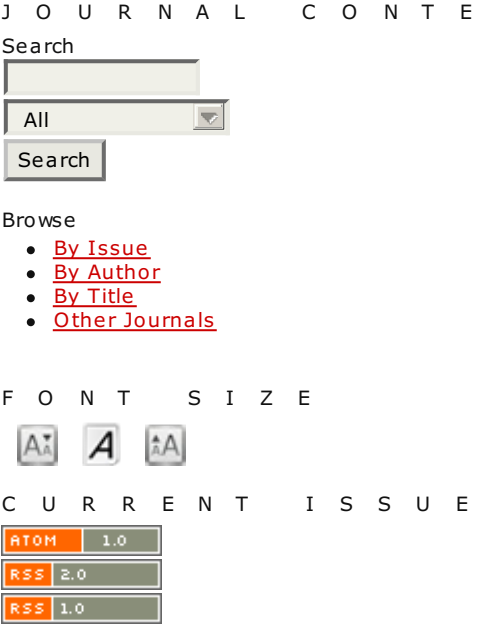

Introduction

Global music sales are presently around \$US 37 billion, however there are indications that physical music sales - predominantly compact discs (CDs), cassettes, and vinyl - have reached a state of market saturation, and may even be declining for some music formats (International Federation of the Phonograph Industry, 2001a). For example, Diebold, a leading German management and technology consultancy company, observed that global music sales fell from $\$ 41.5$ billion in 1995 to $\$ 38.5$ billion in 1999 (Diebold, 2001). This downward trend is recently evidenced in U.S. music sales. The Recording Industry Association of America's (2001a) recently released mid-year sales figures show that music product shipments decreased from $\$ 6.2$ billion at mid-year 2000 to $\$ 5.9$ billion at mid-year 2001 , a decline of 4.4 per cent. A major contributor to this downturn was the fact that the dollar value of compact disc (CD) single sales declined by 28.2 per cent in the first half of 2001 (when compared to the same time period in 2000), owing in part to the availability of free online music (Recording Industry Association of America, 2001b). By 2001, an estimated 30 million American adults - 29 percent of all adults - had downloaded music files over the Internet (Graziano and Rainie, 2001). Younger Americans are even more likely to download music, with 53 percent of those aged between 12 and 17 (over seven million) saying that they have downloaded music. This phenomenon is of particular concern to the music industry as these young consumers may, when they enter the workforce, continue to obtain music for free. There is already evidence that younger consumers are purchasing less music. Between 1991 and 2000 , the overall market share of young consumers has declined substantially; from 18 . percent to 12.9 percent for 15 to 19 year olds, and from 17.9 percent to 12.9 percent for 20 to 24 year olds (Recording Industry Association of America, 2000c). Understandably, these research findings raise concerns about the future of music as a product, particularly with regard to young consumers, whose future music purchasing habits are being influenced by the availability of free music over the Internet.

Offsetting these concerns about the future of music as a product is the fact that delivery of music over the Internet (i.e., music as a service) is expected to expand significantly over the next five vears (Pfahl, 2001). For example, sales of diaital downloads are forecasted to 
increase from $\$ 22$ million in 2001 to $\$ 1.6$ billion in 2006 . However, most online music sales will come from subscription services, which are forecast to increase from $\$ 56$ million in 2001 to $\$ 2.3$ billion in 2006 (New Media Music, 2001). The increasing role of the Internet in the distribution of music is transforming the music industry from an oligopolistic, highlyconcentrated industry characterized by significant barriers to entry, to one in which - as we have seen with Napster - every user is also a potential distributor.

In this paper I demonstrate that social and technological factors are playing a major role in this transformation of the music industry. Digitization, compression, and streaming technologies facilitate these changes. Also, broadband technology and the increasing "ubiquity" of the Internet provide opportunities for delivery of music to devices such as mobile phones. Combined with these technological trends has been an increase in the availability of free music, and in the willingness of consumers to obtain such music. These forces have reduced costs and barriers to entry. In the course of this paper, I will discuss the major technological and social drivers that are prompting the music industry to develop new business models.

Technological Drivers of Change

\section{Digitization and compression technologies}

Most music is presently sold, stored, and consumed in a digital format (typically CDs). For example, the National Association of Recording Merchandisers (1999) reports that 91 percen of all revenues received by music retailers derive from sales of CDs. One key attraction of such digital media for consumers is that the recording quality does not deteriorate from copy to copy or from transmission to copy (Carton, 2000). In contrast, analog recordings - such as those used in vinyl records and audiocassettes - deteriorate in quality over time (Blunt, 1999). While digital music is attractive in terms of the quality of the listening experience, music in a digital form has facilitated the development of the downloading phenomenon that is at the center of the major transformation of the music industry. Also, compression technologies such as MP3, Liquid Audio, and a2b have put music within the reach of those with computers. In particular, MP3 technology permits the compression and transmission of "near" CD-quality sound (Dabeau, 2000) music files over the Internet. MP3 was developed by the Motion Pictures Expert Group (MPEG) of the International Standards Organization (ISO). MP3's origin in itself is significant, as the development of the technology occurred externally to the music industry. Also of note is that the technology was not developed specifically for the compression of music files - this is an unintended application of MP3 (the technology was actually developed to facilitate the development of the interactive television industry; see Leyshon, 2001).

In any event, MP3 technology has played a key role in radically changing the music industry and has become the de facto standard among online music fans (including copyright pirates) (Zeidler, 2000; de Fontenay et al., 1999). Consumers can transform, or "rip" compact discs into MP3 files, save the MP3 files on their own computer or a Web site, and make these files publicly available (Pohlmann, 2000). As Selby (2000) observes:

"... [t]ransferring digital copies requires only a phone call to an Internet Service Provider and either the maintenance of a private FTP [File Transfer Protocol] server, or the uploading of the files to another server. Consumer access can be done anonymously and can be converted into an automated process with very little difficulty or time investment and at minimal expense" [1].

In short, file compression technologies assist users in downloading music. Through these technologies, users can compress files for downloading, thereby saving storage space (Gerbert, 2000). Indeed, the MP3 technology allows users to compress audio files into a digital format that takes up only one-twelfth of the computer storage space of previous technologies (Fisher, 2000). For example, using MP3 technology, a three-minute song would require about 32 megabytes of disk space in its uncompressed form; however, the MP3 enables one to compress the same song into about three megabytes (Dabeau, 2000).

Downloading allows consumers to achieve other efficiencies as well, since users acquire only what most appeals to them (Gross, 1998). Hence, the typical focus in online music is the individual song, rather than the album (Gerbert, 2000). The music industry has historically forced consumers to buy music they do not desire so that consumers can hear the music in which they are interested (Berst, 2000), but these new technologies free consumers to choose the music that most interests them. As William Fisher (2000) notes, the availability of music on the Internet democratizes music, giving consumers the ability to become producers of sorts. Fisher emphasizes that consumers now can manipulate music, recombine different pieces, or even combine downloaded music with their own material.

An additional attraction for those individuals who download music is that they can more readily customize their collections than they can with music that is in a tangible medium. As one commentator emphasizes, "CDs put an arbitrary limitation on how music is packaged. MP3 format dispenses with that. Users can buy music in packages as great or small as they like" (Berst, 2000). The advent of CD recordable (CD-R) devices similarly heightened the desirability of downloading music from the Internet. Using these devices users can download music and "burn" it onto a recordable CD (Webb, 2000). This disc can then be played in a traditional CD player (for example, on a stereo, portable CD player, or in a motor vehicle). Software allowing users to "rip", or copy, tracks from compact discs and post them online is also available (Rao, 1999).

This ability to compress digital music allows consumers to conserve (physical) space. Because items are stored in a virtual rather than a tangible form, consumers do not have worries about where to put their music collections within their home, office, or car. Digital music further enables consumers to manage their music collections in differing ways - for instance, they can group songs in a manner that makes sense to them (Cartwright, 2000). Finally, digital music allows for the potential delivery of music to multiple points, such as to a car, different rooms in a home, or to a mobile telephone (Smith, Salvatore and Phillips, 2001).

Digital and compression technologies take on added significance because they facilitate the online piracy of music. Piracy of physical formats (CDs, audio cassettes) has always existed, but the advent of MP3 technology means that music piracy in the virtual world is reaching levels far greater than that possible with physical products (Magex, 2000). Widespread access to the Internet has also contributed to this increased music piracy. The Pew Internet \& American Life Project estimates that 56 percent of American adults (over 104 million persons) and 45 percent of American children (over 30 million) have Internet access (Rainie and Packel, 2001). One estimate puts copyright infringement of music on the Internet in excess of $\$ 10$ billion (Magex, 2000).

Historically, when analog recordings were commonplace, music labels were not greatly 
perturbed about piracy, owing to the inferior copies that resulted from duplicating recordings. However, with the advent of digital technologies (in particular, the compact disc and, more recently, MP3 and similar technologies) the music industry is more concerned than ever with the potential detrimental impact on revenues that this ostensible copyright infringement represents (Gerbert, 2000). As one commentator states:

"... the capability to create an unlimited number of perfect copies increases the likelihood that [illegal copying] will only increase, thereby diverting revenue from sales of authorized copies from those who own the copyrights" [2]

In sum, the advantages derived from the duplication of copyrighted music virtually guarantee that the practice will continue, since digital downloading provides a number of benefits for music listeners that recordings in traditional tangible formats (compact discs, digital audio tapes, and audio cassettes) cannot, or do not. The good news for the major labels is that they can offer the same benefits to consumers and be able to add more value for music listeners than the providers of free music can. However, to do this the major labels need to adopt new business models.

\section{Streaming Media}

In addition to the advances that allow for the downloading of music, another key technology has emerged, namely streaming media. As with digital downloads, streaming media - owing to the virtual nature of the music delivery - similarly reduces barriers to entry. Several authors propose that in the future consumers will listen to music with streaming media, not by downloading (May and Singer, 2001; National Association of Recording Merchandisers, 2000). An estimated 36 percent of U.S. homes already have access to streaming media (Covell, 2001). Streaming technologies such as those provided by RealNetworks (RealPlayer), Apple (QuickTime) and Microsoft (Windows Media Player) download audio files using buffered play (Covell, 2001). In this technology, music is downloaded portion by portion into a computing device's Random Access Memory (RAM). While the performance of the first portion is playing, the next portion is downloading (Auf der Maur, 1999). Hence, the process of streaming is distinct from downloading of entire files onto a user's hard drive, the method that the users of Napster and other peer-to-peer technologies engage in.

There are several reasons why streaming media, rather than downloads, may become the primary means of delivery for music in the future. First, transferring MP3 files from one computer to another (as is necessary when downloading) can be a time-consuming and messy process. Furthermore, downloading music files is not very attractive to computer users with slower Internet connections. For example, emusic, an online subscription service, notes that downloading a three-minute song on a 56.6 modem should take about 7-8 minutes or about 15-20 minutes for those with (the more common) 28.8 modem connection (emusic.com, 2001). Downloading music is, then, attractive for only those consumers with high-speed Internet connections; and while the market penetration of such connections is increasing, these are still relatively uncommon. Indeed, fewer than 10 percent of persons in the U.S. have such connections; and even fewer people in other countries have access to such technologies (May and Singer, 2001). As streaming media does not involve the downloading of complete music files for repeated listening, these time-related concerns are reduced. Also, owing to the success of the litigation against Napster, for downloaders to continue their activities, they must gravitate to other peer-to-peer networks - such as Gnutella - which tend to be more difficult, and slower, to use.

Downloading technologies and streaming technologies represent only two aspects of the continuing development of the Internet. Indeed, the evolution of the Internet itself and the "ubiquity" of the Internet - that is occurring through the Internet's increasingly common links to mobile telephones and computing devices - also offer opportunities for the music industry, and provide another major impetus for the music industry to explore new business models.

\section{Evolution of the Internet/convergence}

The Internet continues to evolve rapidly. Further developments for the downloadable music industry include broadband technology that permits faster downloading and the integration of Internet technology into mobile devices (Gerbert, 2000). Jupiter Media Metrix (2000) estimates that in the United States, eight million households currently have broadband access via their personal computers (cited in Magex, 2000). Forecasters moreover suggest market penetration for broadband will increase to 15 million users by 2003 (Magex, 2000). This upswing is significant in light of the historical role that broadband has played in the popularity of downloading music over the Internet, especially on college campuses (Coats et al., 2000; Magex, 2000). A survey of students at the University of Southern California found that the downloading of MP3 files was significantly correlated with access to high-speed Internet connections. For example, only 52 percent of those with a bandwidth of less than $56 \mathrm{k}$ downloaded MP3s, compared to 85 percent of those with access to high-speed T1 connections (Latonero, 2000). Given the pervasiveness of high-speed Internet connections at colleges and universities, it is hardly surprising that an estimated 37 percent of users of software such as Napster and Gnutella are students (Rainie, Fox and Lenhart, 2000). In the year 2000, 18-to25 -year-old males had the highest user penetration for Napster (Jupiter and Media Metrix, 2000). However, the development of broadband technology will make downloading more popular among all consumers, given such technology's capacity to reduce the time involved with downloaded (Auf der Mauer, 1999). Increased broadband access also will provide greater opportunity for mobile devices to deliver music to consumers (Rawolle and Hess, 2000).

In addition to the increased speed associated with broadband technology, the other major trend that has significance for the music industry is the convergence of computers and telecommunications. This development is important because it increases the overall speed and flexibility of communications. As Robert Picard observes:

"The most revolutionary aspect of the technology is that it creates new economies of scope and integration that change the economics of content distribution. New technologies permit the combination and integration of the other existing means of communications and allow readers/viewers/listeners more control and choice. It provides different methods for participating in and receiving communication. These changes ... create a significantly different relationship than exists between users and traditional media. It is ignorance or misunderstanding of this essential demand element that has made it so difficult for many firms to find ways to profitably exploit the potential of the new information and communications technologies and associated products and services" [3].

This convergence takes on special meaning in the context of music listening devices. As Ponce [4] notes, "a variety of consumer devices will be able to deliver services previously spread across only one or a few specific functions". Also, these devices are increasingly able to store more and more music. The first mobile MP3 devices could only hold around one hour of CD-quality music (in the form of MP3 downloads). Today, the Rio MP3 player can store up 
to twelve hours of music, downloaded as MP3 files from CDs or the Internet. The development of in-car devices that will enable a driver to listen to a CD-R that contains 12 hours of compressed digital music presumably will fuel consumers demand for such instruments. Mobile telephones are also available for downloading and listening to music. For example, the Samsung Uproar allows consumers to download and listen to around ten hours of music (Samsung, 2001).

In addition to the benefits associated with increased playing time, the availability of mobile devices enables consumers to have greater flexibility as to where they listen to music. One reason that consumers purchase music (as opposed to listening to it for free on the radio o elsewhere) is to gain temporal control, i.e., to control when and where we listen to music (Lacher, 1989). Mobile devices have enabled downloadable music to be enjoyed and played anywhere. This development is important, as listeners are no longer tied to a single source, namely personal computers, for such music (Beverly, 1999). Mobile devices are of particular interest to the music industry, given than that of PCs. For example, the Gartner Group (2001) projects that in 2001 alone global mobile phone sales will exceed 500 million units. If the predicted functional convergence between Persona Digital Assistants (PDAs) and mobile phones is already occurring (Rawolle and Hess, 2000). May and Singer [5] propose that "[s]oon, not just your PC but also your home and car stereo systems and your Walkman will be able to access the Net. Music will be available anywhere you want it". Also, wireless PDAs are expected to grow rapidly during the next three years (Senn, 2000). Popular PDA devices such as Palm computers can access the Internet and play MP3s. Handspring PDA devices currently have an MP3 plug-in allowing users to store between 30 and 60 minutes of music (Welte, 2000).

These widespread technological changes - streaming, downloading, increased bandwidth, and convergence of technologies - provide the means by which music can be obtained in a different format than has historically been the case. However, the availability of free music poses a considerable challenge to the music industry in developing profitable and competitive business models. As I will discuss later, the challenge for the music industry is to construct business models that both exploit these emerging technologies and appeal to listeners more than piracy does.

Social Drivers of Change

\section{Access to free music}

As discussed earlier, the development and rapid adoption of peer-to-peer technologies - such as Napster, Freenet, Aimster, and Gnutella - have provided music lovers with greater access to free music than ever before. Through these technologies, Internet users can search for music on the hard drives of other users, and then download this music to their own hard drives at no cost (Foege, 2000). Viewing these technologies as a form of electronic piracy, the major music labels fear the impact that such so-called "peer-to-peer" technologies will have on their ability to generate sales from their artists. At the forefront of this concern is the Recording Industry Association of America (RIAA), a trade group representing the U.S. recording Industry. The RIAA has pejoratively characterized Napster as a "movement for free music" (Reuters, 2000). Selby (2000) similarly notes that online music piracy is primarily driven by ease of access to music that is free. These fears are not unfounded as the threat posed by downloadable music is more significant than the previous illegal copying engaged in by consumers. Take, for example, the music industry's campaign against "home taping" in the 1970s. Andrew Leyshon (2001) observes that home taping tended to be localized among groups of friends and colleagues. Clearly, this is not the case with those using peer-to-peer technologies, which enable consumers to download music from people they have never met, in locations to which they may never venture.

Given these distinctions, it is hardly surprising that the incidence of piracy is higher on the Internet than that directed toward physical recordings. A recent report by the International Federation of the Phonograph Industry estimates that worldwide piracy for physical recordings is around 36 percent, whereas the Internet is almost totally a medium used for piracy (International Federation of the Phonograph Industry, 2001b). In fact, the idea behind Napster, the most publicized and widely-used peer-to-peer technology, is to allow people to connect to a computer network and freely trade songs. Napster thus operates through a shared server that lists addresses so that individual users can download music on the hard drives of other users. Owing to its appeal, Napster became the fastest growing Internet program in history. In order to prevent, or at least limit, what it viewed as music piracy, the RIAA pursued MP3 and Napster so as to obtain judicial pronouncements that would set a precedent for Web-based music (Lee, 2001). This litigation was successful; and, in February 2001, the Ninth U.S. Circuit Court of Appeals issued a ruling that requires Napster to prevent users from trading copyrighted music (Maples, 2001). The MP3 lawsuit resulted in the largest amount of statutory damages in copyright history, $\$ 100$ million (Band, 2001). The Napster suit also resulted in an injunction directing Napster to block the sharing of specific music files after receiving appropriate notice from the copyright holders (in most cases, the record companies) (Napster.com, 2001). The lawsuit against Napster appears to have successfully reduced the usage of that particular peer-to-peer service. Webnoise Research (2001b) reports that the number of songs downloaded using Napster was 360 million in May 2001 down 87 percent from a peak of 2.79 billion songs downloaded in February, before the ruling took effect.

Despite this litigation against Napster, other sites providing free of charge peer-to-peer services still exist. A key feature of two such sites, Freenet and Gnutella, is that, unlike Napster, they are decentralized peer-to-peer networks. Napster operates a directory service of sorts, whereby users are connected with one another through Napster's centralized server. In contrast, Freenet and Gnutella have no centralized server; rather, each employs "intelligent routing and caching so that a file can move from PC to PC anonymously, making it virtually impossible to identify who posts or downloads a transmitted file" [ㅌ]. The software for these decentralized peer-to-peer networks is freely available from dozens of sites. Users who download this software then can find and connect to other users of the software who may have music or other information of interest to them (Kover, 2000). Freenet in fact describes its software as:

$$
\begin{aligned}
& \text { "... a distributed decentralized information storage and retrieval system. It is } \\
& \text { designed to allow the free distribution of information on the Internet without } \\
& \text { fear of censorship. To achieve this it provides anonymity to those placing } \\
& \text { information into Freenet, and those accessing information from Freenet. It is } \\
& \text { also totally decentralized, nobody is in control of Freenet, not even its creators. } \\
& \text { This makes is virtually impossible to force the removal of a piece of information } \\
& \text { from the system" (Freenet, 2001). }
\end{aligned}
$$

The traditional music industry is particularly threatened by the possibilities of these peer-topeer technologies because one of its key consumer groups, those under 18 , are highly 
computer-literate and, typically, are not old enough to obtain a credit card (Garlick, 2000), thereby ostensibly reducing their ability to make purchases over the Internet. Given this widespread availability of free music, one observer suggests that:

"... [t]he challenge confronting the recording industry is how to prevent unauthorized copying while still offering the consumer an Internet product he or she is willing to pay for" [7].

This formidable challenge derives from the fact that the much-publicized lawsuit against Napster and the other so-called pirates will not stop the proliferation and growth of other peer-to-peer software. Compared to decentralized peer-to-peer software, Napster provided an easy target for the music industry to pursue through the legal system: Napster is a company, and it keeps a central listing of users and their corresponding directories. However, Gnutella, for example, is not a company: It is a software program with over thirty variations, many of which are located in territories beyond the reach of U.S. copyright laws. The decentralized nature of Gnutella therefore makes it impossible to track users (Leung and Lombardi, 2001). Moreover, former Napster users are not oblivious to the existence of other online alternatives sources of free music. For example, a WebNoise Research (2001a) survey of 2,989 college students asked the students how they would access music online in the absence of Napster. Overall, 78 percent said they would gravitate to other free-access sources. Only 21 percent would gravitate to sites with legitimate MP3s, such as emusic.com and mp3.com.

Simply put, the Internet poses a severe threat to the current structure of the music industry. In particular, the protection of intellectual property rights on the Internet is difficult, if not impossible. Should the music industry decide to use litigation as its primary tool for combating the rise of downloading technologies - as it did in the Napster case - the widespread use of peer-to-peer technologies, combined with technological advances, virtually guarantees a staggering number of lawsuits that may overwhelm the judicial system (Magex, 2000). As Reyburn (2000) observes, there is no centralized control for the Internet; and users can take undertake numerous tactics to maintain anonymity and thus, for example, avoid service of proces. In any event, decentralized peer-to-peer networks have large numbe event, decentralized peer-to-peer networks have large numbers of users who - even if they were identifiable by the music industry - would be extremely costly to pursue through the legal system (Band, 2001). Furthermore, efforts by record companies to stop the distribution of copyrighted recordings through MP3.com and Napster have proved to be a public relations disaster. Of particular concern to the music labels is the fact that the industry's response to the Napster infringements has damaged their reputation and relationship with young consumers, the industry's most desired market segment (Leung and Lombardi, 2001). For example, a survey by Quicktake in May 2000 found that over 50 percent of online users believed that the lawsuits filed by the music industry against MP3 and Napster for copyright infringement were unjustified (Tom, 2000). Ultimately then, litigation will not prove effective in combating the distribution of free music on the Internet. Put differently, as Cary Sherman observes, "Litigation is not a business strategy. Ultimately the best response to online piracy is a legitimate alternative" [8].

\section{Cultural and attitudinal concerns}

It bears mentioning that the enabling role played by technology and the mere availability of free music in itself are not of paramount concern to the music industry. Rather, it is the availability of free music, when combined with consumer attitudes towards stealing copyrighted music that is of most relevance. In short, an attitudinal change has accompanied the growth of the Internet, namely the belief that information should be free (Sylva, 2000) This is part of a zeitgeist that leads to a denial of ethical issues surrounding obtaining music and other services online without paying. As early as 1996 - in the days before Napster and MP3 - Adam Segal observed that "[c]yberspace has bred an entitlement philosophy in Internet users. The prevailing dogma is that anything available over the Internet - text, graphics, music, software, etc. - is free, or at least should be" [9]]. More recently, Mia Garlick has suggested that:

"... [the] [g]rowth of the Internet has also seen the rise of a hacker mentality and an entitlement philosophy. The majority of Internet users expect information and particularly music to be free. They also feel entitled to access such information or music regardless of any technological protection measures. This is partly reflected in the share and swap practices made possible by Napster and the popularity of MP3" [10].

In short, the culture of the Internet in general, and of music lovers in particular, contributes to an ethos that encourages universal access to music. Thomas Dolby Robertson opines that music is "essentially a tribal, participatory medium. Fans love to mingle and immerse music is "essentially a tribal, participatory medium. Fans love to mingle and immerse themselves in music" (Robertson, 2001). Likewise Frith (1992) proposes that one of the
pleasures derived from listening to music is that it signals the identity of the listener by indicating membership to a particular social group, subculture or "tribe". Recently, industry commentators suggest that peer-to-peer file sharing is primarily a social phenomenon, that is, "an almost instinctive behavior of many Internet users" [11]. Given the belief of many individuals that information should be freely available and the passion many share for music, it is hardly surprising that the use of peer-to-peer services have become extremely popular (Lenhart and Fox, 2000; Rainie, Fox and Lenhart, 2000).

Furthermore, the very nature of downloadable music leads to different consumer perceptions as to theft. A survey by the Pew Internet $\&$ American Life Project found that 78 percent of Internet users who download music do not believe that it is stealing to save music files to their computer hard drives (Lenhart and Fox, 2000). This same survey found that 61 percent of those who download music do not care if the music they download is copyrighted. Also, a Quicktake.com survey in the U.S. found that 80 percent of online users do not consider that it unethical to either download or share free digital music files (Tom, 2000). This attitude is underscored by the following response: "I understand that it might be the same thing as going into a store and swiping a CD, but when you're on a computer and the song is right there to copy and sample, you don't see it as taking from somebody" (anonymous selfreport, quoted in Carlson, 2000). Likewise, another commentator, Simon Shull Foust (2000) states that:

"Yes, if I walk into Virgin Records and take a plastic disk and walk out without paying, that is shoplifting. Yes, when I download a copyrighted music file from the Internet without permission and without paying, I have infringed on the copyright holders rights. But in each of these cases, the music is not stolen. The supply has not decreased, in fact it has increased, and so has the demand."

Attitudes towards large businesses similarly have an impact on the willingness of individuals to download free music. The presumed wealth of large corporations, such as the so-called "Big Five" music labels, makes them ready targets for piracy. Many consumers regard large organizations as abusing power (Greenberg and Scott, 1996), an attitude that is redolent of earlier times. As Fisher and Withey note, as early as the 1950s, one could regard:

$" . .$. the bulk of arguments in disfavor [of organizations originate from] the 
Leung and Lombardi (2001) propose that the ability of peer-to-peer technologies such as Napster to provide a sense of exchanging information without any mediating entity "plays well with the anti-corporate values of young people" [13]. Hence, many consumers - especially the more youthful ones mentioned earlier - rationalize such practices as downloading as paybacks for years of corporate overreaching and greed. In the United States in particular the Federal Trade Commission's finding that music labels had engaged in the practice of inflating compact disc prices and had denied those music retailers who sold compact discs at lower levels cooperative advertising payments has likewise reinforced consumer perceptions of overpricing and abuse of market power (Pitofsky et al., 2000). In this regard, Leung and Lombardi (2001) observe that the downloading of MP3 files is not merely about piracy, but actually may involve a form of protest against music companies, specifically the charging of unjustifiably high prices. For example, Latonero's (2000) survey of University of California students found that 50 percent said that CDs were "expensive"; 14 percent "very expensive"; 33 percent "reasonably price[d]" and 3 percent "inexpensive". In another study - by the Music Industry News Network (2000) - 74 percent of the respondents asserted that CDs were not reasonably priced in the offline retail market. Such shifts in the dominant cultural ethos therefore make the challenges facing the music industry even more ticklish.

In the next section of this paper I discuss the impacts that technological and social forces are having on the music industry.

\section{Discussion and Conclusions}

The major record labels, the so-called "Big Five" (BMG Entertainment, Sony, AOL Time Warner, EMI and Vivendi Universal Music Group), sell over 80 percent of popular music (Coats et al., 2000). Historically, the Big Five have effectively controlled most of the music supply chain (Hill, 2000). Also, contractual arrangements between record labels and artists have historically formed a major barrier to entry in the music industry as well. These arrangements, in essence, provide labels with monopoly rights to the artistic output of individual artists from which the labels can then generate revenues. In particular, copyrights held by music labels comprise a key means by which music labels protect their economic assets, i.e. their investments in artistic talent (Sadler, 1997). As Andrew Leyshon observes, "the ability to exploit profits has been central to the profits of the music industry almost since its very inception" [14]. Today, however, the revenue streams that accrue to those who control musical copyrights are threatened by the increasing popularity of online music piracy.

Aside from the barrier to entry traditionally posed by copyrights, it is clear that the influence of the Big Five have over the music industry has had several other consequences:

1. It has been hard for small record companies to survive;

2. artists have had limited control over the distribution of their music

3. high levels of industry concentration - the extent to which the major music labels dominate the industry, as measured by relative market share - have resulted in fewer releases of new recordings; and

4. it has been difficult for music consumers to obtain the music content without purchasing it through approved channels, typically retailers or music clubs (Black and Greer 1987; Cartwright 2000; Rothenbuhler and Dimmick, 1982).

With regard to the latter factor, the distribution of music, the "Big Five" typically sell music directly to large retailers, or through large intermediaries to a vast array or local retailers (Coats et al., 2000). Furthermore, the Big Five have made significant investments in the distribution infrastructure to support the manufacture, distribution, and retailing of music (Alexander, 1997; Selby, 2000). As one online music company, Emusic.com, observed in its 1999 Annual Report:

"Historically, the major record labels have been reluctant to participate in any alternative distribution model which would restructure the current music distribution hierarchy [This reluctance is] due to their investment in the current physical distribution infrastructure and their relationship with the retail channel" [15]

Put differently, technological changes have increasingly resulted in heightened competition for the major labels. In fact, the distribution of music over the Internet only requires a single master copy, whereas distribution of music as a product requires distribution of numerous (physical) items, i.e., CDs, audio cassettes, etc. When music is stored and sold as a computer file, disintermediation occurs (the cutting out of middle layers of distribution channels). This is particularly harmful to the Big Five, who, as Alexander $(1994,1997)$ note are also the major to retail stores. Economies of products have historically placed smaller, independent music labels at a disadvantage to the Big Five (Alexander, 1997). However, the Internet significantly reduces the Big Five's market power in the area of distribution. As Coats et al. (2000) observe:

$" . . .[t]$ he Internet's influence on the music industry is especially significant because it has the potential to change an industry controlled by a few record labels that have been consistently able to sustain high profit margins. These record labels seemed invincible due to significant statutory protection as well as a solid, tightly controlled method of distribution. However, digital distribution the delivery of downloaded music from the Internet - is threatening to change this well-established system" [16].

Simply put, recent market entrants that utilize digital downloading technology (notably Napster and MP3), represent a much more formidable potential threat to the labels control over the distribution of their artists' works. Downloadable music and its associated technologies have brought about a redistribution of power from major record companies to music consumers and, arguably, artists. In any event, digital technologies and the Internet have radically altered the value chain for the music industry in a number of ways that reduce costs and barriers to entry. Among other things, this shift provides many more opportunities for independent music labels to diminish the major labels' historical hegemony over traditional distribution methods.

Historically, independent music labels have provided an alternative avenue to the Big Five for artists to get their music to the marketplace. True, owing to the high costs associated with promotion and distribution, it has been rare for independent labels to reach the large audiences of the Big Five (Coats et al. 2000). Furthermore, the independents have audiences of the Big Five (Coats et al., 2000). Furthermore, the independents have historically relied on the Big Five to distribute music products by independent artists. However, owing to the cost reductions made possible through the distribution of music via the Internet. In the case of one such label, AtomicPop, lower overhead permits the offering of royalties in excess of 50 percent of revenues, compared with the 21-22 per cent that labels typically 
offered (Brull, 1999). Also, to illustrate the influence of the Internet on the redistribution of market power, one need only consider the case of Matador Records. The co-head of this company, in claiming that the traditional model (i.e., the major labels distributing music to retail stores) was not working well for independent artists, has noted that "online distribution removes much of the power of the major labels, traditionally grounded in control of physical distribution and radio access" [17].

In addition to providing higher royalties and additional opportunities to sign with independent labels, an enticing lure to would-be artists, digital technologies make the production and commercialization of music easier and less costly. For example, May and Singer (2001) propose that of the $\$ 15$ that consumers typically spend on a CD, around $\$ 9$ has the potential to be "redistributed" if electronic distribution channels are used: $\$ 1$ in costs associated with the manufacture of CDs, $\$ 1.40$ associated with their physical distribution, $\$ 2.25$ in promotional dollars (as the Internet will allow for more targeted marketing), and $\$ 4$ of the promotionaldollars (as the internet will allow for more targeted marketing), and $\$ 4$ of the Internet enable artists and intermediaries to undertake distribution and marketing activities more cheaply. Indeed, a key attraction of the Internet is that it enables practically anyone to distribute music, thereby undermining the control that the major labels have historically had on this marketplace (Gerbert, 2000).

Additional issues of relevance to the cost structure of music labels involves cost savings associated with inventory control and having a more informed basis for deciding which artists careers to invest in. Music labels presently need to forecast how many copies of a compact disc that consumers will purchase. Inaccurate estimates can lead to over- or underproduction, a problem that would not occur were music distributed digitally via the Internet (Fisher, 2000). Furthermore, downloadable music makes it easier for record companies in general, and smaller labels in particular, to compete without concerns about physical inventory. Simply put, online labels do not have the significant costs that major labels incur with regard to manufacturing, distribution, and retailer inventory-holding costs (Brull, 1999). For example, LiquidAudio comments that, "[b]y eliminating inventory concerns we give every indie [independent] label and garage band the ability to make its music available for purchase" (Freund, 1997). Also, distributing music digitally could enable music labels to better estimate the likely success of artists whose careers they have chosen to promote. At present as John Lovering (1998) observes, "... investment is shaped by highly subjective corporate projections regarding future consumption patterns" [18]. However, in an online environment music labels would be better able to predict individual consumer preferences, thereby be able to make more informed decisions as to which artist's careers to develop to meet consumer needs. This, in essence, lowers the costs associated with activities that can be thought of as research and development by the music labels.

In summary, Internet-based business models [19] appeal to the music industry because even if they were to lower prices - they still could increase their present profit margins.

"(Re)production, modification, storage and distribution of digital products is (almost) free of costs. In the long run the only relevant costs remaining will be creative talent, original production, marketing/'context creation' (e.g., graphics, video clips, background information; also generating increasingly important cross-selling revenue) and intellectual property protection/authorization" [20].

About the Author

Mark Fox is Associate Professor of Management \& Entrepreneurship in the School of Business \& Economics at Indiana University South Bend.

Web: http://www.iusb.edu/ mfox1

E-mail: $\underline{\text { mfox1@iusb.edu }}$

Acknowledgments

The author wishes to thank Brenda Knowles and Fred Naffziger, Professors of Business Law at Indiana University South Bend, for helpful suggestions on earlier drafts of this paper.

Notes

1. Selby, 2000 , p. 10

2. Reyburn, 2000, p. 997.

3. Picard, 2000, pp. 60-61.

4. Ponce, 1999, p. 68

5. May and Singer, 2001, p. 132.

6. Pohlmann, 2000, p. 59

7. Op.cit.

8. Sherman, 2001 , p. 36

9. Segal, 1996, p. 99.

10. Garlick, 2000, p. 2

11. Wharton, 2001, p. 1

12. Fisher and Withey, 1951 , p. 15.

13. Leung and Lombardi, 2001, p. 19

14. Leyshon, 2001, p. 52

15. Emusic.com, 1999, p. 5

16. Coats et al., 2000, p. 285

17. Foege, 2000, p. 162.

18. Lovering, 1998 , p. 33

19. The development of business models for the music industry is beyond the scope of this paper. Interested readers are referred to Diebold (2001), Fisher (2000), Fox (2002), Fox and 
Wrenn (2001), May and Singer (2001), Singh (2001), and Wendkos (2001).

20. Gerbert, 2000 , p. 3.

References

P. Alexander, 1997. "Product Variety and Market Structure: A New Measure and a Simple Test," Journal of Economic Behavior and Organization, volume 32, pp. 207-214.

P. J. Alexander, 1994. "Entry Barriers, Release Behavior and Multi-Product Firms in the Music Recording Industry," Review of Industrial Organization, volume 9, pp. 85-98.

R. Auf der Maur, 1999. "Internet Distribution of Music Performances," International Business Lawyer (April), pp. 165-189.

J. Band, 2001. "The Copyright Paradox: Fighting Content Piracy in the Digital Era," Brookings Review, volume 19 , number 1, pp. 32-34.

J. Berst, 2000. "What the Recording Industry must do to Survive," ZDNet (July 5), at http://www.zdnet.com.

P. Beverley, 1999. "Protecting Copyright, Increasing Choice and Generating Revenue from the Internet," text of speech by Peter Beverly to Music.Net conference, London, 10 December, at http://www.magex.com.

M. Black and D. Greer, 1987. "Concentration and Non-Price Competition in the Recording Industry," Review of Industrial Organization, volume 3, pp. 13-37.

R.M. Blunt, 1999. "Bootlegs and Imports: Seeking Effective International Enforcement of Copyright Protection for Unauthorized Musical Recordings.," Houston Journal of International Law, volume 22, number 1 (Fall), pp. 169-208.

S.V. Brull, 1999. "A Rock ' $n$ ' Roll Vet Takes to Cyberspace to Challenge the Music Industry," Business Week (12 February), at http://www.businessweek.com/bwdaily/dnflash/feb1999/nf90212b.htm, accessed 1 February 2002.

S. Carlson, 2000. "Get Ready for an Encore to the Napster Controversy," Chronicle of Higher Education (8 September), and at http://chronicle.com/free/v47/i02/02a05101.htm, accessed 1 February 2002.

S. Carton, 2000. "Will the Digital Music Industry Survive?" at

http://www.clickz.com/tech/lead edge/article.php/829761, accessed 1 February 2002.

S.D. Cartwright, 2000. "Napster: A Business in Search of a Viable Model," Journal of Business Strategy volume 21, number 5 (September/October), pp. 28-32.

W.S. Coats, V.L. Freeman, J.G. Given, and H.D. Rafter, 2000. "Streaming into the Future: Music and Video Online," Loyola of Los Angeles Entertainment Law Journal, volume 20, pp. 285-307.

A. Covell, 2001. "Reel 'Em In!," Network Computing (19 February), pp. 46-63, and at http://www.networkcomputing.com/1204/1204f1a2.html, accessed 1 February 2002.

J. Dabeau, 2000. "MP3," at http://eon.law.harvard.edu/h2o/property/MP3/main.html, accessed 1 February 2002.

E. de Fontenay, S., de Fontenay, R., Kibbee, R. and S. Shulman, 1999. "MP3: Digital Music for the Millennium?" at http://www.musicdish.com/survey/download/mp3report.pdf, accessed 1 February 2002.

Diebold, 2001. "Wanted: A Survival Plan for the Music Industry: Chapter One: Problem Areas of the Recording Industry," at http://www.musicdish.com/, accessed 1 February 2002.

emusic.com, 2001. "Frequently Asked Questions about EMusic," at http://www.emusic.com/help/faq.html, accessed 1 February 2002

emusic.com, 1999, "Annual Report," at http://www.emusic.com/about/investor/, accessed 1 February 2002.

W. Fisher, 2000. "Digital Music: Problems and Possibilities," at

http://www.law.harvard.edu/Academic_Affairs/coursepages/tfisher/Music.html, accessed 1 February 2002

B.R. Fisher and S.B. Withey, 1951. Big Business as the People See It: A Study of Socioeconomic Institution. (Survey Research Center series, publication number 6). Ann Arbor, Mich.: Survey Research Center, Institute for Social Research, University of Michigan.

A. Foege, 2000. "Beyond Napster: Free Music and the Death of the Album," Spin (15 August), pp. $159-162$.

M.A. Fox, 2004. "E-Commerce Business Models for the Music Industry," Popular Music and Society, volume 27 , number 2, pp. 112-119.

M.A. Fox and B. Wrenn, 2001. "A Broadcasting Model for the Music Industry," JMM: The International Journal on Media Management, volume 3, number 2, pp. 112-119, also at http://www.mediajournal.org, accessed 1 February 2002

Freenet, 2001. "Frequently Asked Questions," at http://freenetproject.org/cgibin/twiki/view/Main/FAQ, accessed 1 February 2002.

J. Freund, 1997. "Garage Bands go Global," Wired, at http://www.wired.com/wired/archive/5.02/beta.html, accessed 1 February 2002.

S. Frith, 1992. "The Cultural Study of Popular Music," In: L. Grossberg, C. Nelson, and P. Treichler (editors). Cultural Studies. New York: Routledge, pp. 174-181.

M. Garlick, 2000. "Pricing Recorded Music in an Online World," at http://www.gtlaw.com.au/, accessed 1 February 2002.

Gartner Group, 2001. "Gartner Dataquest says Worldwide Mobile Phone Sales to Surpass a Half Billion Units in 2001," press release of 20 March, at http://www.gartner.com, accessed 1 February 2002

P.A. Gerbert, 2000. "Music - The Prototype for the Digital Economy," Highlights from the Digital Marketplace, volume 1 OC\&C Strategy Consultants. 
J. Greenberg and K.S. Scott, 1996. "Why do Workers Bite the Hands that Feed Them? Employee Theft as a Social Exchange Process," Research in Organizational Behavior, volume 18, pp. 111-156.

R.D. Gross, 1998. "Right Here, Right Now: The New Music Industry," Multimedia and Entertainment Law Online News, volume 4, number 404, at http://www.ibslaw.com/melon/archive/404 newmusic.html.

R.J. Hill, 2000. "Pirates of the 21st Century: The Threat and Promise of Digital Audio Technology on the Internet," Santa Clara Computer and High Technology Law Journal, volume 16 (May), pp. 311-343.

International Federation of the Phonograph Industry, 2001a. "Recording Industry World Sales 2000," at http://www.ifpi.org, accessed 1 February 2002.

International Federation of the Phonograph Industry, 2001b. "IFPI Music Piracy Report," June, at http://www.ifpi.org.

Jupiter and Media Metrix, 2000, "Jupiter: U.S. Online Music Market to reach $\$ 5.4$ Billion in 2005, led by industry shift to digital subscriptions," at http://news.excite.com.

A. Kover, 2000. "Napster: The Hot Idea of the Year," Fortune (June), pp. 129-136, and at http://www.business2.com/articles/mag/0,1640,7968,00.html, accessed 1 February 2002

K.T. Lacher, 1989. "Hedonic Consumption: Music as a Product," Advances in Consumer Research, volume 16, pp. 367-373.

M. Latonero, 2000. "Survey of MP3 Usage: Report on a University Consumption Community," Norman Lear Center, Annenberg School of Communication, University of California, at http://entertainment.usc.edu/publications/mp3.pdf, accessed 1 February 2002.

H.C. Lee, 2001. "Making the Net Safe for Record Labels," The Standard (12 February), at http://www.thestandard.com, accessed 1 February 2002.

A. Lenhart and S. Fox, 2000. "Downloading Free Music: Internet Music Lovers Don't Think It's Stealing," Pew Internet \& American Life Project's Online Music Report, at http://www.pewinternet.org, accessed 1 February 2002.

L. Leung and R. Lombardi, 2001. "MP3: Music for the Masses," Risky Business, issue 2a, pp. 18-20, at http://www.pwcqlobal.com/, accessed 1 February 2002.

A. Leyshon, 2001. "Time-Space (and Digital) Compression: Software Formats, Musical Networks, and the Reorganization of the Music Industry," Environment and Planning A, volume 33, pp. 49-77, and also

http://www.cybersalon.org/cybersalon/resources/paper1.html, accessed 1 February 2002.

J. Lovering, 1998. "The Global Music Industry: Contradictions in the Commodification of the Sublime," In: A. Leyshon, D. Matles, and G. Revill (editors). The Place of Music. New York: Guilford Press, pp. 31-56.

Magex, 2000. "Online music piracy, 'I fought the law and the law ...'," at http://www.magex.co.uk, accessed 1 February 2002.

J. Maples, 2001. "Napster gets Played," Red Herring (14 February), at http://www.redherring.com/industries/2001/0214/ind-napster021401.html, accessed 1 February 2002.

B. May and M. Singer, 2001. "Unchained Melody," McKinsey Quarterly, number 1, pp. 128-137, also at http://www.mckinseyquarterly.com, accessed 1 February 2002.

Music Industry News Network, 2000. "MI2N Survey Results: Retail CD Pricing," at http://www.mi2n.com.

Napster.com, 2001. "District Court Preliminary Injunction," at http://www.napster.com/pressroom/legal.html, accessed 1 February 2002.

National Association of Recording Merchandisers, 2000. "Creating Industry Value from Digital Music Distribution," September (NARM/Emerald Research), at http://www.narm.com, accessed 1 February 2002.

National Association of Recording Merchandisers, 1999. "NARM 1999 annual survey results," at http://www.narm.com/programs/research/surv99/99AnnualSurvey72.pdf, accessed 1 February 2002

New Media Music, 2001. "Online Music to Become a $\$ 10$ Billion Business by 2006," (Informa Media Group), at http://www.newmusicmedia.com.

M. Pfahl, 2001."Giving Away Music to Make Money: Independent Musicians on the Internet." First Monday, volume 6, number 8 (August), at http://firstmonday.org/issues/issue6_8/pfahl/ accessed 1 February 2002.

R.G. Picard, 2000. "Changing Business Models of Online Content Services," JMM: International Journal on Media Management, volume 2, number 2, pp. 60-68, also at http://www.mediajournal.org, accessed 1 February 2002

R. Pitofsky, S.F. Anthony, M.W. Thompson, O. Swindle and T.B. Leary, 2000. "Statement of Chairman Robert Pitofsky and Commissioners Sheila F. Anthony, Mozelle W. Thompson, Orson Swindle, and Thomas B. Leary In the Matter of Sony Music Entertainment, Inc.; In the Matter of Time Warner, Inc.; In the Matter of BMG Music, d.b.a. "BMG Entertainment"; In the Matter of Universal Music \& Video Distribution Corp. and UMG Recordings, Inc.; and In the Matter of Capitol Records, Inc., d.b.a. "EMI Music Distribution" et al.," Docket Nos. C-3971, C-3972, C3973, C-3974, and C-3975, File No. 971-0070, at http://www.ftc.gov/os/2000/09/musicstatement.htm, accessed 1 February 2002.

K.C. Pohlmann, 2000. "Music Wars," Scientific American, volume 283, number 5, pp. 56-60.

B. Ponce, 1999. "The Impact of MP3 and the Future of Digital Entertainment Products," IEEE Communications, volume 37, number 9 (September), pp. 68-70.

L. Rainie and D. Packel, 2001. "More Online, Doing More," Pew Internet Tracking Report, Pew Internet \& American Life Project, at http://www.pewinternet.org/reports/index.asp/, accessed 1 February 2002.

L. Rainie, S. Fox, and A. Lenhart, 2000. "13 Million Americans 'Freeload' Music on the Internet; One Billion Free Music Files Now Sit on Napster Users' Computers," Pew Internet Tracking Report, Pew Internet \& American Life Project, at 
http://www.pewinternet.org/reports/index.asp/, accessed 1 February 2002.

B. Rao, 1999. "The Internet and the Revolution in Distribution: A Cross-Industry Examination," Technology in Society, volume 21, number 3, pp. 287-306.

J. Rawolle and T. Hess, 2000. "New Digital Media and Devices," JMM: International Journal on Media Management, volume 2, number 2, pp. 89-109, also at http://www.mediajournal.org, accessed 1 February 2002.

Reuters, 2000. "Record Industry Ready to Share Tunes," at http://www.pcworld.com.

S.B.A. Reyburn, 2000. "Fair Use, Digital Technology, and Music on the Internet," University of Pittsburgh Law Review, volume 61, pp. 991-1022.

Recording Industry Association of America, 2001a. "2001 RIAA Midyear Statistics," at http://www.riaa.org/pdf/midyear 2001.pdf, accessed 1 February 2002.

Recording Industry Association of America, 2001b, "Recording Industry Releases 2000 Manufacturers' Shipments and Value Report," at http://riaa.org/MD-Tracking.cfm, accessed 1 February 2002.

Recording Industry Association of America, 2001c, "The Recording Industry Association of America's 2000 Consumer Profile," at http://riaa.org/PDF/2000 consumer profile3.pdf, accessed 1 February 2002.

T.D. Robertson, 2000. "The Upside of Music on the Web, Part Two," at http://www.riaa.org/Guest Column0301.cfm, accessed 1 February 2002.

E.W. Rothenbuhler and J.W. Dimmick, 1982. "Popular music: concentration and diversity in the Industry, 1974-1980," Journal of Communication, volume 32, number 1, pp. 143-149.

D. Sadler, 1997. "The global music business as an information industry: reinterpreting economics of culture," Environment and Planning A, volume 29, pp. 1919-1936.

Samsung, 2001. "Samsung Uproar: Features," at http://www.samsungtelecom.com/uproar/features.html, accessed 1 February 2002.

A.P. Segal, 1996. "Dissemination of Digitized Music on the Internet: A Challenge to the Copyright Act," Computer and High Technology Law Journal, volume 12, pp. 97-138.

J. Selby, 2000. "The Legal and Economic Implications of the Digital Distribution of Music: Part One," Entertainment Law Review, volume 11, number 1, pp. 4-10.

J.A. Senn, 2000. "The Emergence of M-commerce," Computer, volume 33, number 12 (December), pp. 148-150.

W. Shaw, 2001. "I want my MP3," Q (May), pp. 84-89.

C. Sherman, 2001. "Music on the Internet: A New World is Waiting," Brookings Review, volume 19 , number $1, \mathrm{pp} .35-37$, also at http://www.brookings.edu/press/REVIEW/winter2001/sherman.htm, accessed 1 February 2002.

W. Smith, K. Salvatore, K. and J. Philips, 2001. "Ultimate MP3 Showdown," Maximum PC, volume 6 , number 3 , pp. 28-40.

A. Singh, 2001. "Cutting through the Digital Fog," at http://www.bain.com/bainweb/about/insights/pract_insights.asp, accessed 1 February 2002

J.B. Sylva, 2000. "Recent trends in copyright law; relevant technologies and emerging business models," Loyola of Los Angeles Entertainment Law Journal, volume 20, pp. 217-241.

J. Tom, 2000. "QuickTake Snap Shot: It's Okay to Download Free Music Files According to $80 \%$ of Online Music Users," at http://www.quicktake.com/qt/static/files/DigitalMusicFinal.pdf, accessed 1 February 2002.

S.W. Webb, 2000. "RIAA v. Diamond Multimedia Systems: The Recording Industry Attempts to Slow the MP3 Revolution - Taking Aim at the Jogger Friendly Diamond Rio," Richmond Journal of Law and Technology, volume 7, number 1, at http://www.richmond.edu/jolt/v7i1/note2.html, accessed 1 February 2002.

Webnoise Research, 2001a. "How will you Acquire Music in the Absence of Napster," at http://www.webnoise.com/research/.

Webnoise Research, 2001b. "Webnoize Estimates Napster Downloads Down 87\%," Media Center, Press Release (5 June), http://www.webnoise.com//mediacenter.rs.

J. Welte, 2000. "Devices," Business 2.0 (18 August), at http://www.business2.com/archives.

E. Wendkos, 2001. "Digital Music and New Media: Legal Issues vs. Business Practices," at http://www.musicdish.com/mag/?id=4240, accessed 1 February 2002.

Wharton, 2001. "Napster or Not, Online Sharing will Thrive," at http://knowledge.wharton.upenn.edu, accessed 1 February 2002.

S. Zeidler, 2000. "BMG Launches Download Venture with Lycos," (10 October), at http://www.excite.com/news.

Editorial history

Paper received 4 December 2001; accepted 25 January 2002.

\section{Contents Index}

Copyright @2002, First Monday

Technological and Social Drivers of Change in the Online Music Industry by Mark Fox First Monday, volume 7, number 2 (February 2002),

URL: http://firstmonday.org/issues/issue7_2/fox/index.html 
Web2PDF converted by Web2PDFConvert.com 